\title{
ASO Visual Abstract: Tumor Burden Dictates Prognosis Among Patients Undergoing Resection of Intrahepatic Cholangiocarcinoma: A Tool to Guide Post-Resection Adjuvant Chemotherapy?
}

\author{
Diamantis I. Tsilimigras, MD, and Timothy M. Pawlik, MD, MPH, PhD, FACS, FRACS (Hon.) (1) \\ Department of Surgery, Division of Surgical Oncology, The Ohio State University Wexner Medical Center and James \\ Comprehensive Cancer Center, Columbus, $\mathrm{OH}$
}

The role of overall tumor burden (TB) in intrahepatic cholangiocarcinoma (ICC) remains poorly defined. In our recently published article (https://doi.org/10.1245/s10434020-09393-7), we demonstrated that TB dictated prognosis among patients with resectable ICC. In particular, TB was independently associated with both overall survival (medium-TB: $\quad \mathrm{HR}=1.40,95 \%$ confidence interval $[\mathrm{CI}]$
1.14-1.71; high-TB: $\mathrm{HR}=1.89,95 \% \mathrm{CI} 1.46-2.45)$ and disease-free survival (medium-TBS, HR $=1.61,95 \% \mathrm{CI}$ 1.33-1.96; high-TB: HR $=2.03,95 \%$ CI 1.56-2.64) following ICC resection. Adjuvant chemotherapy was associated with a greater survival among patients with high TB. TB may be used as a tool to help guide post-resection treatment strategies.

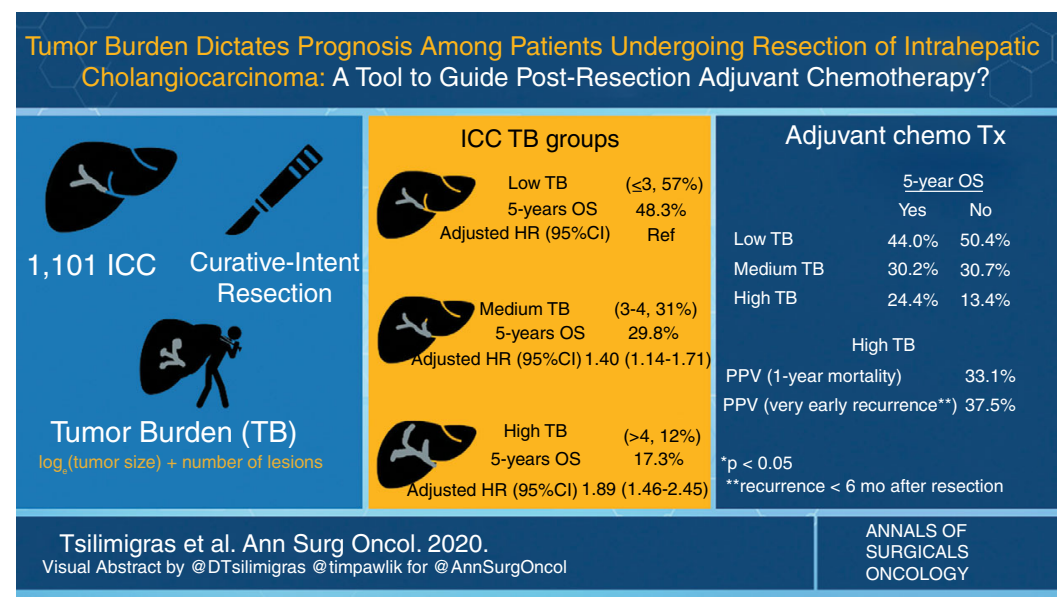

(C) Society of Surgical Oncology 2021

T. M. Pawlik, MD, MPH, PhD, FACS, FRACS (Hon.)

e-mail: tim.pawlik@osumc.edu

DISCLOSURE The authors report no disclosures.

Publisher's Note Springer Nature remains neutral with regard to jurisdictional claims in published maps and institutional affiliations. 